\title{
A cortical multi-layered model and the properties of its internally-generated activity
}

\author{
Rodrigo FO Pena*, Renan O Shimoura, Antonio C Roque \\ From 24th Annual Computational Neuroscience Meeting: CNS*2015 \\ Prague, Czech Republic. 18-23 July 2015
}

The cerebral cortex displays a rich repertoire of internally-generated dynamic states even in the absence of external stimuli [1]. Most theoretical studies of cortical activity are based on networks of randomly connected units [2] or with architectures artificially built from random networks [3]. In spite of the usefulness of these models, it is also important to have computational models that try to accurately represent cortical network architecture. Recently, Potjans and Diesmann [4] presented a network model of the local cortical microcircuit based on extensive experimental data on the intrinsic circuitry of striate cortex. The model is a fullscale representation of the cortical network under a surface area of $1 \mathrm{~mm}^{2}$ of striate cortex ( 80,000 neurons) and contains two cell types (excitatory and inhibitory) distributed over four layers: L2/3, L4, L5, and L6. The cells are modeled as current-based leaky integrate-andfire neurons with exponential synaptic currents. In this work, we used the connectivity map of the Potjans and Diesmann model [4] to construct a cortical model with 4,000 neurons (i.e. with the number of cells reduced by a factor of 20 in comparison with the Potjans and Diesmann model). Cells were described by the Izhikevich model [5] with parameters adjusted so that excitatory neurons were of the regular spiking (RS) type, $50 \%$ of the inhibitory neurons were of the fast spiking (FS) type and the other $50 \%$ of the inhibitory neurons were of the low-threshold spiking (LTS) type. Synapses were modeled as conductance-based with exponentially decaying conductances (we used the same synaptic parameters as in [3]). Instantaneous excitatory/inhibitory synaptic increments were denoted by $g_{\text {ex }} / g_{\text {in }}$. Brief $(10 \mathrm{~ms})$ but strong direct current pulses were applied to $15 \%$ of L4 excitatory cells to stimulate the network and, after

\footnotetext{
* Correspondence: rfdop20@gmail.com

Departamento de Física, FFCLRP, Universidade de São Paulo, Ribeirão Preto,
} SP, Brazil

stimulus removal, we kept the simulation running until $T_{\text {sim }}=3000 \mathrm{~ms}$. We performed this experiment for 10 different initial conditions to randomize the construction of the network as well as for at least 100 different combinations of $g_{\text {ex }} / g_{\text {in }}$ in the range $g_{\text {ex }}=[0,0.1], g_{\text {in }}=$ $0[1]$. The measurements taken were the lifetime of network activity, the activity of the network and the coefficients of variation of the interspike intervals of network neurons. In addition, we performed the same experiments with L4 isolated and in all possible combinations (in pairs or triplets) with the other layers, and with $100 \%$ of inhibitory cells of the FS type.

The major results of our simulations are: (1) For networks made of RS and FS cell types, long-lived network activity was observed for combinations of $g_{\text {ex }} / g_{\text {in }}$ in the region of highest values of both of them. These states displayed irregular neuronal firing. For other combinations of $g_{\text {ex }} / g_{\text {in }}$ the network activity decayed rapidly after a short transient; (ii) Introduction of LTS neurons increased the region of $g_{\text {ex }} / g_{\text {in }}$ combinations that generated long-lived activity and reduced the average network firing rate; (iii) Different combinations of layers favored more or less the occurrence of long-lived activity. L4 alone, L4-L5 and L4-L5-L6 could not sustain long-lived activity while L4-L6 and L23-L4-L6 displayed long-lived activity for larger regions of $g_{\text {ex }} / g_{\text {in }}$ combinations.

\section{Acknowledgements \\ Work funded by FAPESP-DFG (IRTG 1740/TRP 2011/50151-0) and FAPESP/ CEPID/Neuromat (grant 2013/07699-0). RFOP is supported by a FAPESP PhD scholarship (grant 2013/25667-8), ROS is supported by a CAPES MSC scholarship, and ACR is supported by a CNPq research grant (PQ 306251/}

Published: 18 December 2015

\section{References}

. Vogels TP, Rajan K, Abbott LF: Neural network dynamics. Annu Rev Neurosci 2005, 28:357-376. 
2. Kriener B, Enger H, Tetzlaff T, Plesser HE, Gewaltig M, Einevoll GT: Dynamics of self-sustained asynchronous-irregular activity in random networks of spiking neurons with strong synapses. Front Comput Neurosci 2014, 8:136.

3. Tomov P, Pena RFO, Zaks MA, Roque AC: Sustained oscillations, irregular firing, and chaotic dynamics in hierarchical modular networks with mixtures of electrophysiological cell types. Front Comput Neurosci 2014, 8:103.

4. Potjans TC, Diesmann M: The cell-type specific cortical microcircuit: relating structure and activity in a full-scale spiking network model. Cereb Cortex 2014, 24(3):785-806.

5. Izhikevich EM: Simple model of spiking neurons. IEEE Trans Neural Netw 2003, 14(6):1569-1572.

doi:10.1186/1471-2202-16-S1-P209

Cite this article as: Pena et al: A cortical multi-layered model and the properties of its internally-generated activity. BMC Neuroscience 201516 (Suppl 1):P209.

\section{Submit your next manuscript to BioMed Central} and take full advantage of:

- Convenient online submission

- Thorough peer review

- No space constraints or color figure charges

- Immediate publication on acceptance

- Inclusion in PubMed, CAS, Scopus and Google Scholar

- Research which is freely available for redistribution

Submit your manuscript at www.biomedcentral.com/submit 